\title{
Selected parameters of concretes containing sludge from wet aggregates grading
}

\author{
Martina Draganovska, Alena Sicakova \\ Technical University of Košice, Civil Engineering Faculty, Institute of Environmental Engineering, Vysokoškolská 4, 04200 Košice, Slovakia
}

\begin{abstract}
The worldwide development of consumer society leads to an enormous increase of the amounts of waste and problems with its deposition. Therefore, the question how to utilize various wastes is still in the focus of research activities. The article represents a contribution to utilization of the sludge - waste produced during the process of wet aggregates grading as a substitute filler in cement composite concrete. For the assessment of the properties of concretes with application of this secondary material as filler, recipes with 30,60 and $100 \%$ replacement of natural fine aggregate were prepared and tested. For an objective determination of the results the reference sample containing only natural aggregates was prepared, as well. The consistency as a parameter of fresh concrete was evaluated during mixing. The following tests were performed after 28 and 90 days of setting and hardening: apparent density, compressive strength, capillarity and frost resistance. A formula with $30 \%$ replacement of fine aggregate reached the best values resulting from performed tests while the samples with 60 and $100 \%$ reached sufficient technical parameters despite worse achievements.

The work has been shown that the tested sludge has a potential to act as filler in concrete. This seems to be one of the options of effective utilization of waste, which is not used commonly in present production of building materials.
\end{abstract}

Keywords: sludge; concrete; fine aggregate.

\begin{tabular}{|ll}
\hline Nomenclature \\
PC & Portland cement \\
NA & Natural fine aggregate \\
RF & Reference sample \\
XRF & X-ray fluorescence analysis \\
XRD & X-ray diffraction anylysis \\
FR & Frost resistance coefficient \\
w & water to cement ratio \\
\hline
\end{tabular}

\section{Introduction}

One of the lines of action explored in connection with sustainable construction is increasing the proportion of reuse, recycling and revaluation of waste generated by our society. The conversion of waste to the valuable resource is one of the fundamental objectives of the "Plan for the efficient use of resources" which is based on European Union policy. Therefore utilization of recycled materials as replacement the natural sources have become more and more popular also in construction industry.

It is evidenced in the many expert studies that the secondary raw materials connected with extraction, processing or liquidation of rocks/ building stone/ aggregates can be successfully used in practice as component of building materials. As an example, the works that investigated quarry dust and marble sludge as a replacement of natural aggregates in concrete can be mentioned here [1-2]. The results of these studies show that this type of waste had a positive impact on the resulting concrete parameters - higher compressive strength and better water resistance. Other experimental studies in this scope focused on testing such materials like: foundry sand, quarry sand, aggregates from excavated soil obtained during construction of roads and tunnels [3-8] show that these kinds of waste despite worse results doesn't show significant limitations for use as a filler in cement composites.

Corresponding author: Martina Draganovska. E-mail address: martina.draganovska@tuke.sk

http://dx.doi.org/10.3846/enviro.2014.016

(C) 2014 The Authors. Published by VGTU Press. This is an open-access article distributed under the terms of the Creative Commons Attribution License, which permits unrestricted use, distribution, and reproduction in any medium, provided the original author and source are credited. 
However, as to the sludge from wet processing of aggregates, the application to cement composites is not general, due to variable parameters. It should respect the kind of rock in the quarry (chemical and mineralogical composition), as well as risk of harmful substances (causing the volume changes or adverse effects on setting and hardening process) presence in the sludge. These parameters highly influence the resulting properties of composites while depending on the quarry conditions, so actual solutions are bound to actual regions.

This study relates to the use of sludge as fine aggregate in concrete. The sludge comes from production of crushed clinopyroxene andesite aggregates by process of wet grading. For the assessment of the properties of concretes with application of this secondary raw material, recipes with 30,60 and 100\% replacement of natural fine aggregate were prepared and tested. The assessment was performed on the basis of following properties: consistency, compressive strength, capillarity and frost resistance.

\section{Experimental investigation}

The experimental study consists of two stages. In the first stage, the properties of fresh concrete were assessed. The second stage was focused on the testing hardened concrete (tests were performed at 28 and 90 days of samples age). For assessment of influence of the sludge on the properties of concretes, recipes with $0,30,60$ and $100 \%$ replacement of fine natural aggregate were designed. Concretes were considered to be tested as frost-resistant, so it was designed for exposure class XF1 in terms of EN 206-1.

\subsection{Materials}

In this experiment ordinary Portland cement (CEM I 42.5), natural fine aggregate fraction 0/4, natural coarse aggregate fraction $4 / 8$ were used, complying relevant standards for concrete production $[9,10]$. The sludge from production of crushed aggregates by process of wet grading (produced by an Eastern Slovakia company) was used. Sludge characteristics were verified previously by tests of sieve analysis, bulk density, chemical and mineralogical analysis, as well as by determination of clay lump and humus content. These characteristics were published in the article [11]. The results showed following:

- grain size: represents the range $0 / 4$ with a high proportion of fine particles,

- chemical analysis (by XRF method): prevalent components are $\mathrm{Si}, \mathrm{Al}, \mathrm{Ca}$,

- mineralogical analysis (by XRD method): the basic minerals are plagioclase, anorthite, silica while sludge doesn't contain any harmful minerals, causing the volume changes or adverse effects on setting and hardening process,

- determination of humus content : sludge doesn't contain any humus,

- determination of clay lumps: sludge doesn't contain any clay lumps.

\subsection{Mix proportion}

For mix proportion of concrete, the quantity of components was determined according to the usual recommendations for concretes of higher quality and according to standard recommendations of EN 206-1 for XF1 exposure class. Here amount of water is limited and water/cement ratio (w) should be 0.6 maximally. Starting value was 0.56 and during mixing it was adjusted to maintain the uniform consistency of concretes containing increasing amount of the sludge (see part 2.3.1). For this purpose, the superplasticizer (polycarboxilate) was applied, too. Grading of aggregates was determined in accordance to EN 206-1 (61\% of $0 / 4$ and $39 \%$ of 4/8) [12]. The principle of testing lies in replacement of fine natural aggregate (0/4) by the sludge in various \% portions (see Table 1). Mix proportions are given in table (Table 1).

Table 1. Mix proportions

\begin{tabular}{|c|c|c|c|c|c|}
\hline & Units & $0 \%$ & $30 \%$ & $60 \%$ & $100 \%$ \\
\hline Cement 42,5 R & {$\left[\mathrm{kg} / \mathrm{m}^{3}\right]$} & 370 & 370 & 370 & 370 \\
\hline Water & {$\left[1 / \mathrm{m}^{3}\right]$} & 252 & 252 & 266 & 333 \\
\hline Water to cement ratio $\mathrm{w}$ & {$[-]$} & 0.56 & 0.56 & 0.60 & 0.60 \\
\hline Natural fine aggregate $0 / 4$ & {$\left[\mathrm{~kg} / \mathrm{m}^{3}\right]$} & 1086 & 760 & 434 & - \\
\hline Sludge & {$\left[\mathrm{kg} / \mathrm{m}^{3}\right]$} & - & 3.26 & 652 & 1086 \\
\hline Natural coarse aggregate & {$\left[\mathrm{kg} / \mathrm{m}^{3}\right]$} & 694 & 694 & 694 & 694 \\
\hline Plasticizer & {$[\%]$} & 0.5 & 1.2 & 1.6 & 2.7 \\
\hline
\end{tabular}

\subsection{Experimental methods}

\subsubsection{Fresh concrete}

Amount of water was optimized in order to obtain uniform consistency, keeping the $\mathrm{w}_{\max }=0.6$. It was verified by two methods: slump cone test- S2 (50-90 $\mathrm{mm})$ required and by flow test - F2 (350-410 $\mathrm{mm})$ required, accordance to [12] - see Table 2 and Figure 2. 


\subsubsection{Hardened concrete}

After fresh concrete optimization, individual mixtures $(0,30,60,100 \%$ replacement of fine aggregate) were filled into

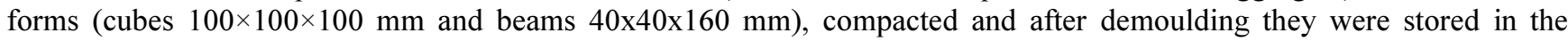
water. Tests performed at 28 days of samples age:

- apparent density [13],

- compressive strength (strength class C 20/25 minimum is required for XF1) [14],

- capillarity (according to national standard [15]), tested under laboratory conditions ( $20^{\circ} \mathrm{C}$ and current pressure) by insertion of samples to the water of $10 \mathrm{~mm}$ depth during $24 \mathrm{~h}$. Results of capillarity were expressed by two methods: by the growth of weight and by the depth of penetration. For this parameter, the specimens were split and the depth of penetration of the waterfront was measured. (see Fig. 5),

- frost resistance (according to national standard and CDF test procedure using alternating of freezing and thawing cycles in a defined time -25 cycles $[16,17]$. The time-temperature cycle is specified in the Figure 1.

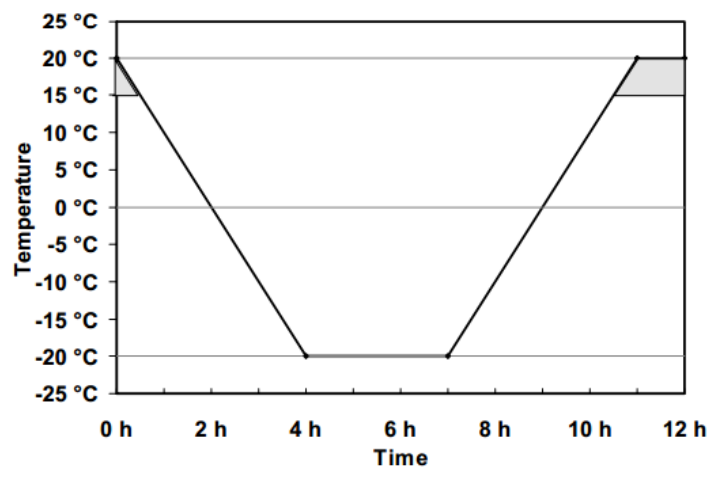

Fig. 1. Time-temperature cycle

The results of the frost resistance are given in the terms of:

- scaling (total mass of sample after freezing cycles related to the total mass of sample before the test, in \%),

- frost resistance coefficient FR (flexural strenght of samples after freezing cycles related to flexural strenght of samples before freezing). Criterion for the frost resistance fulfillment is given by the FR $>85 \%$. The achievement of this limit after 25 freezing cycles allows to assign the sample to XF 1 class according to EN 206-1.

Tests performed at 90 days of samples age:

- apparent density [13],

- compressive strength [14].

\section{Results}

\subsection{Consistency of fresh concrete}

Resulting amounts of water and plasticizer, as well as corresponding consistency are given in table (Table 2). The results of measurements confirm that recipes using sludge aggregate need for bigger amount of water, as well as bigger dosage of plasticizer to achieve the same class of consistency. Further, results of consistency by actual amount of both water and plasticizer show that bigger is the portion of the sludge, worse is the consistency.

Table 2. Results of slump cone test and flow test

\begin{tabular}{llllll}
\hline Method & Units & RF & $30 \%$ & $60 \%$ & $100 \%$ \\
\hline slump cone & {$[\mathrm{mm}]$} & 55 & 50 & 51 & 50 \\
flow & {$[\mathrm{mm}]$} & 397 & 350 & 360 & 350 \\
w & {$[-]$} & 0.56 & 0.56 & 0.6 & 0.6 \\
Plasticizer & {$[\%]$} & 0.5 & 1.2 & 1.6 & 2.7 \\
\hline
\end{tabular}

As it is visible in the Figure 2, sludge filler causes very good plasticity and stability of mixtures, with no any bleeding. 


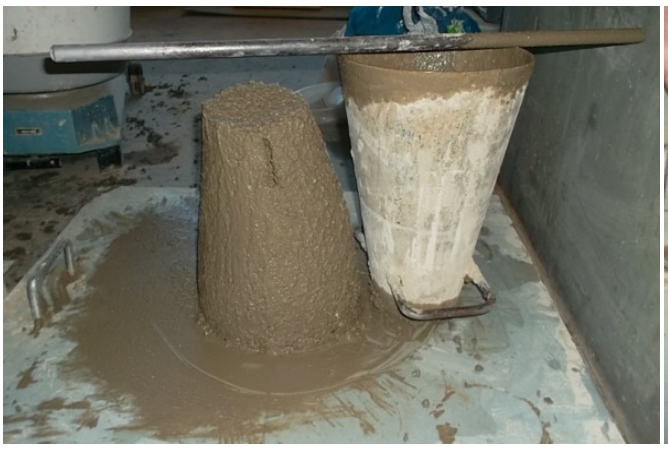

(a)

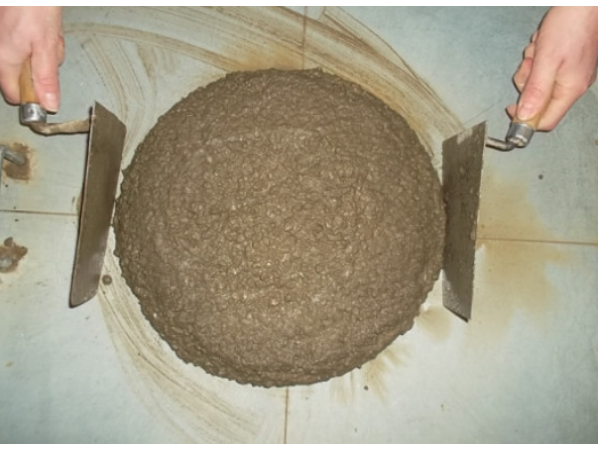

(b)

Fig. 2. Testing consistency by slump cone test (a) and flow test (b)

\subsection{Apparent density and compressive strength}

Results of 28 and 90 day tests of both apparent density and compressive strenght are given in figures (Fig. 3, 4). Findings are following:

- apparent density of all the test samples increased depending on the time,

- the highest density was demonstrated by sample with $30 \%$ replacement of NA after both 28 and 90 daysof setting and hardening,

- the lowest density was demonstrated by sample with $100 \%$ replacement of NA replacement after both 28 and 90 days of setting and hardening.

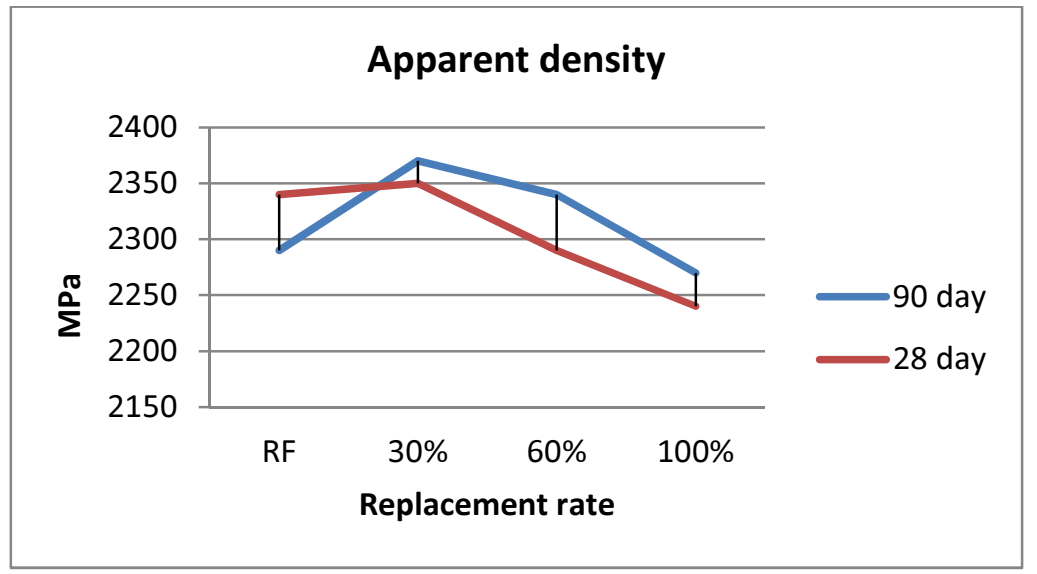

Fig. 3. Comparison the results of apparent density in 28 and 90 day

- strength of all the test samples increased depending on the time,

- the highest 28 day compressive strength was demonstrated by reference sample. Samples with 30 and $60 \%$ replacement of NA achieved higher compressive strength comparing the reference samples after 90 days of setting and hardening,

- the lowest compressive strength was demonstrated by sample with a $100 \%$ replacement of NA.

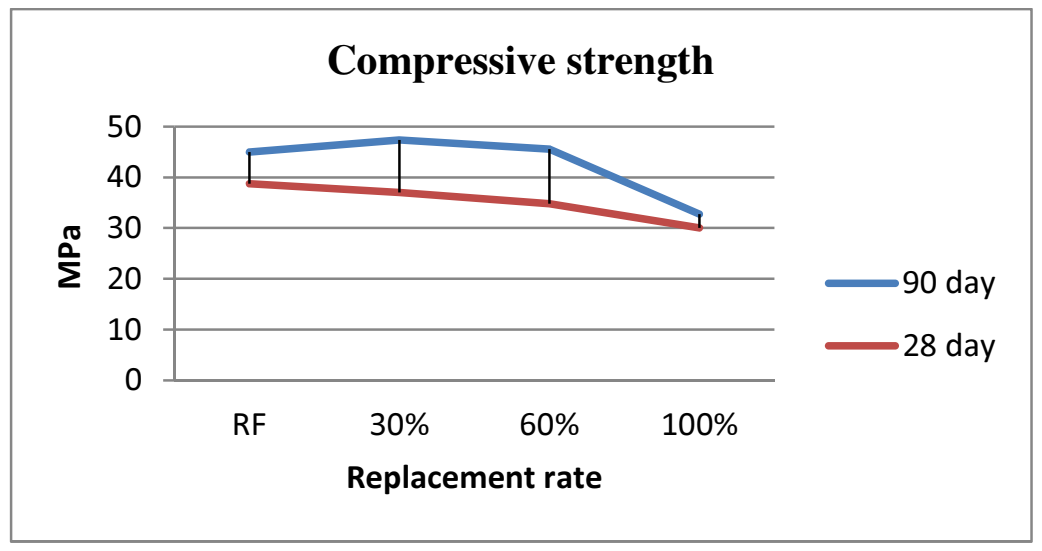

Fig. 4. Comparison the results of compressive strength in 28 and 90 days 


\subsection{Capillarity}

Results of depth of penetration method show a tendency for growing the capillarity with bigger amount of sludge, as well as growth of mass method shows the same tendency, excepting the reference sample. Sample with $100 \%$ replacement of NA replacement achieved the highest capillarity. Results of capillarity by both methods are given in table (Table 3), while figure (Fig. 5) shows the running of the test.

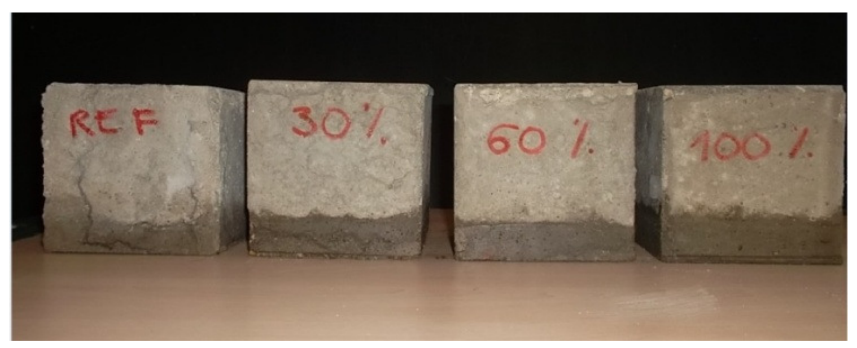

Fig. 5. Samples after 24 hour capillarity test

\subsection{Frost resistance}

Results of individual parameters of frost resistance of samples are given in figure (Fig. 6) and table (Table 3). Findings are following:

- after freeze-thaw test, decrease in the weight for all samples was observed,

- the lowest decrease was observed in the sample with $30 \%$ replacement of NA while the highest decrease was observed in the $100 \%$ one,

- comparing the results of tensile strength of samples a slight decreas in the tensile strength in all samples after freeze-thaw test is visible,

- the biggest decrease was determined in the sample with $30 \%$ replacement of NA, however, the sample reached the highest strength,

- the lowest values were measured at the sample with $100 \%$ replacement of NA,

- all samples are frost resistant for 25 cycles,

- samples with application of sludge are waker in frost resistance comparing the reference sample, excepting recipe with $50 \%$ of NA replacement.

Table 3. Results of the capillarity and frost resistance

\begin{tabular}{|c|c|c|c|c|}
\hline \multirow[t]{3}{*}{ Sample } & \multicolumn{4}{|c|}{ Results of tests } \\
\hline & \multicolumn{2}{|l|}{ Capillarity } & \multicolumn{2}{|c|}{ Frost resistance } \\
\hline & Growth of weight [\%] & Water penetration $[\mathrm{cm}]$ & Scaling [\%] & Coefficient FR [\%] \\
\hline RF & 3.34 & 3.2 & 1.00 & 96.5 \\
\hline $30 \%$ & 2.98 & 3.9 & 0.86 & 89.0 \\
\hline $60 \%$ & 3.8 & 3.9 & 1.07 & 97.4 \\
\hline $100 \%$ & 7.2 & 4.7 & 1.46 & 88.9 \\
\hline
\end{tabular}

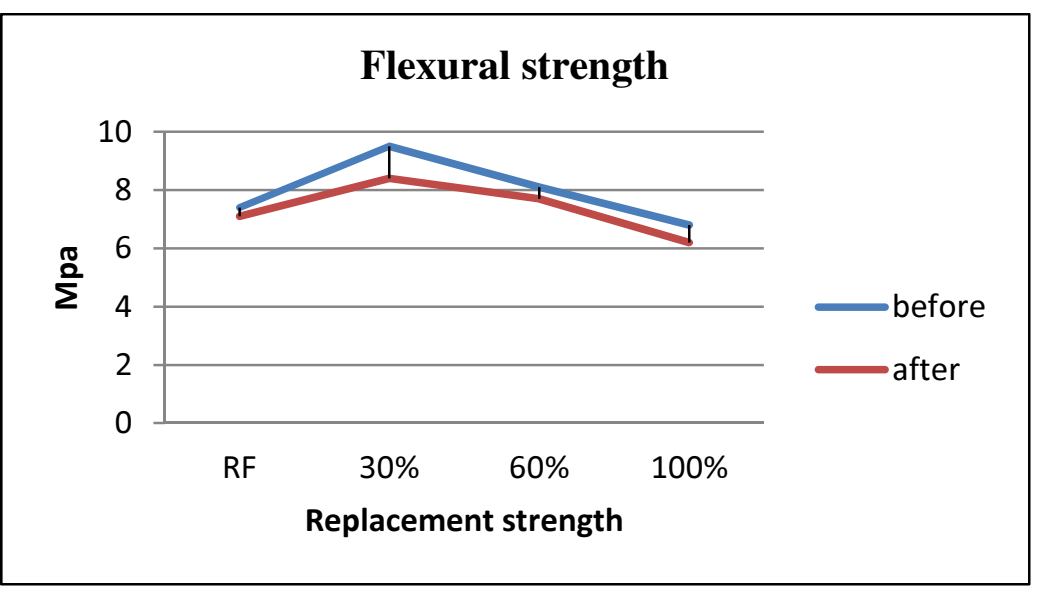

Fig. 6. Results of flexural strength before and after freeze- thaw test 
Analysis of test results allows to state, that compressive strength and apparent density of samples show a correlation compliant to well known theories: decrease in one parameter means decrease in the second one. This is confirmed also by the capillarity tests, pointing to the weaker microstructure of concretes containing sludge through the increasing values of capillarity.

In spite of decreasing trend in properties in relation with increasing portion of sludge, it is to be state, that all tested recipes fulfill the frost resistance criteria for XF1 class (min. C 20/25, FR $>85 \%$ after 25 freeze-thaw cycles). Compressive strength values are even higher than this limit and sufficient for well defined practical uses. The best results of compressive strenght was achieved by sample with $30 \%$ of NA replacement and it falls to class C 30/37. Samples with 60 and $100 \%$ of NA fall to class C $25 / 30$.

Because bigger portions of sludge worsens the consistency, and amounts of water are limited due to EN 206-1, design of concretes for actual exposure classes will need optimization of plasticizers.

\section{Conclusion}

The aim of this paper was to verify the suitability of sludge from wet grading of aggregates as filler in concrete, using selected tests. Methods of experimental works have been applied in accordance with valid standards and also in accordance with knowledge of current trends in the use of secondary raw materials in building materials. Based on the obtained results in this experimental work can be concluded that sludge has the potential to be used as the filler in concrete and it is very promising material for this application, requiring a complex verification.

The major benefits of using this alternative material include the following:

- sludge filler causes very good plasticity and stability of mixtures, with no any bleeding,

- compressive strengths of mixtures using sludge are lower than those of reference mixture, but even $100 \%$ replacement of NA gives a valuable strength around $30 \mathrm{MPa}$,

- sludge filler not prevent for fulfillment of frost resistance criteria for 25 cycles.

Overall, recipes with 60 and $100 \%$ of NA replacement are admissible for evaluation as the most effective samples,which with the sufficient technical parameters give the best environmental benefit, because they reduce depletion of resources, save valuable and vulnerable areas, reduce transport by recycling on the demolition site as well as create sustainable highvalue outlet for the "future of concrete."

\section{Acknowledgements}

This research has been carried out within the Grant No. 1/0767/13 of the Slovak Grant Agency for Science

\section{References}

[1] Menadi, B.; Kenai, S. 2010. Durable concrete with waste crushed quarry sand, in $37^{\text {th }}$ IAHS World Congress on Housing, Santander, Spain, 2010, [online] Available from Internet: http://grupos.unican.es/gted/iahs/esp/archivos/WEB_PROGRAMA\%2029-09-10.pdf. ISBN 978-84-693-66655-4.

[2] Hammed, M.; Shahul, S. 2009. Properties of green concrete containing quarry rock dust and marble sludge powder as fine aggregate, Journal of Engineering and Applied Sciences 4: 83-89.

[3] Naik, T.; Patel,V. 2011. Utilization of used foundry sand in concrete, in Proc. of the $12^{\text {th }}$ International Conference on Environmental Science and Technology, Greece 2011, [online] Available from Internet: http://www.srcosmos.gr/srcosmos/showpub.aspx?aa=15113

[4] Colas, J.; Chaussadent, T.; Divet, L. 2012. Innovative solutions for the use in concrete of excavated materials from Lyon- Turin railway link tunnel, in ICDS 12- International conference, Durable Structures, Lisbon, Potrtugal, 20112. Lisbon: Laboratio nacional de engenharia civil.

[5] Krishamoorthi, A. 2006. Preliminary studies on the dimensional characteristics of quarry dust concrete, International Journal of Applied Engineering Research 7: 1479-1492.

[6] Naik, T.; Kraus, R. 2012. Effects of fly ash and foundry sand on performance of architectural precast concrete, Journal of materials in Civil Engineering 24: 851-859. http://dx.doi.org/10.1061/(ASCE)MT.1943-5533.0000432

[7] Khatib, J.; Herki, B. A . 2013. Capillarity of concrete incorporating waste foundry sand, Construction of building materials 47: 867871. http://dx.doi.org/10.1016/j.conbuildmat.2013.05.013

[8] Basar, H. 2012. The effect of waste foundry sand as a partial replacement of sand on the mechanical, leaching and micro- structural characteristics of ready- mixed concrete, Construction of building materials 35: 508-515. http://dx.doi.org/10.1016/j.conbuildmat.2012.04.078

[9] EN 197-1 2012. Cement.Part 1:Composition, specifications and conformity criteria for common cements. Bratislava: SÚTN.

[10]EN 12620. 2013. Aggregates for concrete. Bratislava: SÚTN

[11]Draganovská, M.; Sicakova, A. 2013. Determination of the bacis characteristics of sludge for utilization in building cement composites. Pollack Periodica, Hungary [in press]

[12]EN 206-1. 2002. Concrete. Part 1. Specification, performance, production and conformit, Bratislava: SÚTN

[13] EN 12390-3. 2010. Testing hardened concrete. Part 3. Density of hardened concrete, Bratislava: SÚTN

[14] EN 12390-3 .2013. Testing hardened concrete. Part 3. Compressive strength of test specimens, Bratislava: SÚTN.

[15] STN 73 1316 . 1989. Determination of moisture content, absorptivity and capillarity of concrete, Bratislava: SÚTN.

[16] STN 73 1322. 1986. Determination of frost resistance of concrete, Bratislava: SÚTN.

[17] Selzer, M.; Fagerland, G. 1996. Freeze-Thaw and deicing resistance of concrete, [online] Available from Internet : https://www.unidue.de/ibpm/Projekte/CDF_eng.pdf 